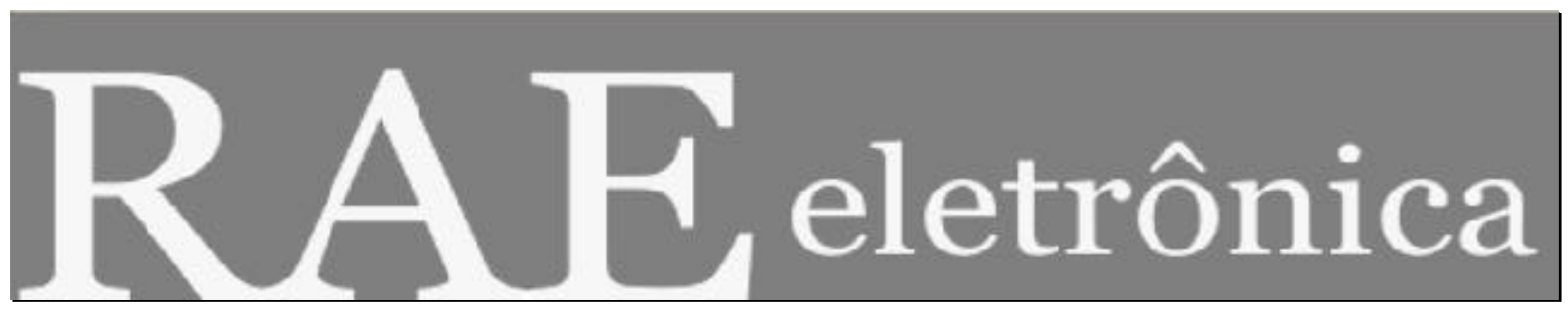

\title{
COMPLEMENTARIDADE ENTRE RACIONALIDADES NA CONSTRUÇÃO DA IDENTIDADE PROFISSIONAL
}

Por:

\section{Sandra Mara Maciel de Lima \\ Kátia Regina Hopfer \\ José Edmilson de Souza-Lima}

RAE-eletrônica, v. 3, n. 2, Art. 19, jul./dez. 2004

http://www.rae.com.br/eletronica/index.cfm?FuseAction=Artigo \&ID=2007\&Secao=GESTREL\&Volume=3 $\&$ Numero $=2 \& A n o=2004$

CCopyright, 2004, RAE-eletrônica. Todos os direitos, inclusive de tradução, são reservados. É permitido citar parte de artigos sem autorização prévia desde que seja identificada a fonte. A reprodução total de artigos é proibida. Os artigos só devem ser usados para uso pessoal e não-comercial. Em caso de dúvidas, consulte a redação: redacao@rae.com.br.

A RAE-eletrônica é a revista on-line da FGV-EAESP, totalmente aberta e criada com o objetivo de agilizar a veiculação de trabalhos inéditos. Lançada em janeiro de 2002, com perfil acadêmico, é dedicada a professores, pesquisadores e estudantes. Para mais informações consulte o site www.rae.com.br/eletronica.

\section{RAE-eletrônica}

ISSN 1676-5648

(C2004 Fundação Getulio Vargas - Escola de Administração de Empresas de São Paulo.

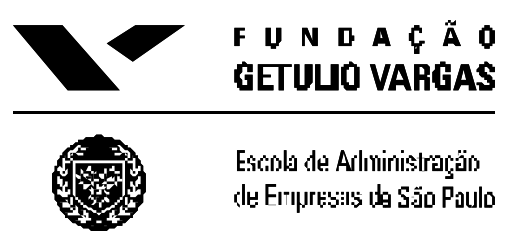




\title{
COMPLEMENTARIDADE ENTRE RACIONALIDADES NA CONSTRUÇÃO DA IDENTIDAD E PROFISSIONAL
}

\section{RESUMO}

A discussão subjacente ao presente artigo está associada ao confronto entre a racionalidade instrumental e a racionalidade substantiva. Partindo deste interminável debate, o texto demonstra que da complementaridade entre as racionalidades instrumental e substantiva emerge uma identidade profissional médica, ainda, predominantemente instrumental, porém, com lampejos de substantividade. Neste estudo de caso, o profissional da saúde escolhido foi o médico. Para tanto, trabalhou-se com entrevistas qualitativas que captaram indicadores da influência das duas racionalidades na formação da identidade deste profissional. Foi possível identificar que, sem desconsiderar a capacidade colonizadora da racionalidade instrumental na imposição de rotinas, hierarquias e fragmentação do conhecimento, são inegáveis os espaços conquistados pela racionalidade substantiva no processo de construção de identidades profissionais auto-realizadas levando o sujeito a repensar sua ideologia no trabalho.

\begin{abstract}
The discussion implied in this paper is associated to the confrontation between instrumental rationality and substantive rationality. Starting from this endless debate, the paper demonstrates that the professional identity that emerges of the complementary aspects between the two rationalities still predominantly instrumental, but with twinkle of substantivity. In this case study, the health professional chosen was the physician. Thus, qualitative interviews were carried out to establish influence indicators for both rationalities in the formation of the identity of this specific professional. It was possible to identify that, regardless the colonization capacity of the instrumental rationality in the imposition of routines, hierarchies and knowledge fragmentation, it is impossible to deny the space conquered by the substantive rationality in the process of construction of self-achieved professional identities, forcing the individual to reconsider his work ideology.
\end{abstract}

\section{PALAVRAS-CHAVE}

Racionalidade instrumental; Racionalidade substantiva; Identidade; Trabalho; Auto-realização.

\section{KEY WORDS}

Instrumental rationality; Substantive rationality; Identity; Work; Self-achievement. 


\section{INTRODUÇÃO}

No período pré-capitalista, a prática médica estava ligada à constituição de um saber 'esotérico', definido por um corpo particular de conhecimentos e de técnicas desconhecidas pela maior parte da população. Este saber propiciava poder e prestígio a quem o possuía.

A transformação do modo de produção capitalista força o Estado a assumir, paulatinamente, as funções de cuidados médicos e de controle. Nesse modo de produção, a medicina perde seu caráter religioso, para articular-se direta ou indiretamente com a esfera produtiva. Não é mais a salvação das almas mas a conservação e adaptação da força de trabalho às exigências de uma economia de reprodução ampliada.

Em estudo realizado no setor de saúde municipal de Minas Gerais, Cotta et al(1999), mostra que, além das ações do serviço de saúde não terem sido alteradas, de curativas-individuais para coletivas-preventivas, o setor público também passou a priorizar as intervenções curativas. O locus de prestação de serviços curativos foi transferido do hospital para os postos públicos de saúde. Em consequiência, o setor público implementou os serviços que seguem a lógica da produção-produtividade. Isto é revelado por meio da imprensa que noticia, por um lado, os avanços da medicina e, por outro, o rompimento da tradicional relação médico-paciente. Os processos, denúncias e escândalos envolvendo médicos, odontólogos, psicólogos, enfermeiros são cada vez mais freqüentes, revelando o estranhamento das partes no que diz respeito à ética, à confiança e à credibilidade no tratamento proposto. "A cumplicidade até então existente entre as partes foi rompid a”. (Machado, 1995, p.56).

A subjetividade, característica peculiar da relação médico-paciente, cede lugar à objetividade racionalizadora. Obedecendo às novas normas administrativas, os médicos são compelidos a adotar atitudes que mais os assemelham a técnicos burocraticamente controlados do que a profissionais que detêm autonomia técnica.

A identidade aqui é entendida não como entidade autônoma, estática e duradoura, mas como processo de construção, atividade humana, mediada pelo uso da linguagem e ligada à socialização do indivíduo por meio da interação simbólica com seu meio. Desta forma, durante a existência do indivíduo, a identidade pode ser adquirida e perdida, passando por períodos de autenticidade e falsidade (Caldas \& Wood Jr, 1997).

No entendimento de autores como Guerreiro Ramos (1989), Serva (1997), a sociedade do produtivismo prioriza a racionalidade como instrumento para uma maior eficiência e eficácia, provocando mudanças no mundo do trabalho em prol de maior competitividade empresarial. Nesta perspectiva, este estudo tem a intenção de demonstrar que da complementaridade entre as racionalidades instrumental e substantiva emerge uma identidade profissional médica, ainda, predominantemente instrumental, porém, com lampejos de substantividade. Para tanto, toma-se como referência uma instituição médico-hospitalar da região Metropolitana de Curitiba.

Neste artigo, a racionalidade instrumental está associada ao conjunto de crenças e valores que rege a sociedade moderna, direcionando-a exclusivamente para o cálculo; a racionalidade substantiva está associada ao conjunto de crenças e valores que transcende ao cálculo; a identidade profissional se constitui sempre a partir da relação com o outro sujeito; e a auto-realização se refere ao sentimento de satisfação do indivíduo.

$\mathrm{Na}$ primeira parte do artigo apresenta-se o debate sobre as racionalidades, passando pela origem clássica do 
conceito de razão; na segunda trata-se dos efeitos da racionalidade instrumental sobre a civilização do trabalho: reestruturação produtiva, a revolução tecnológica e o processo de trabalho na saúde; na terceira, discute-se o conceito de identidade e de que forma ela se constrói no contexto do trabalho; na quarta, faz-se o detalhamento da metodologia utilizada; na quinta, apresenta-se o resultado das entrevistas e, finalmente, na última parte são esboçadas algumas conclusões e sugestões para novos estudos.

\section{O DEBATE EM TORNO DA RACIONALIDADE SUBSTANTIVA}

Não existem duas ou mais razões, mas apenas a Razão Humana. Para os primeiros homens na Grécia antiga que se ocuparam do tema não havia a distinção entre, por exemplo, a capacidade de calcular e a de ser prudente. Para Aristóteles (1999), por exemplo, não se pode ser prudente sem ser bom, assim como não se pode ser bom sem ser prudente. Portanto, a noção clássica de razão tende a associar substantividade com calculabilidade sem hierarquia ou predomínio abusivo de um dos domínios sobre o outro e, ainda, associar a razão diretamente ao indivíduo, nunca fora dele (Souza-Lima, 2002).

"Para Guerreiro Ramos, é inaceitável a premissa que sustenta a ciência social moderna: a de que a razão está na sociedade e na natureza, não no indivíduo" (Souza-Lima, 2002). Tanto que seus estudos sobre a racionalidade nas organizações apresenta a razão substantiva como sua principal categoria de análise, sendo ela um atributo natural do ser humano, residindo na psique. Por meio desta razão os indivíduos poderiam alcançar sua auto-realização.

A sociedade industrial e suas organizações instituíram o trabalho como um dos valores sociais fundamentais, criando a sociedade da tecnosfera, do produtivismo desenfreado. "Nela, os indivíduos são avaliados socialmente em função do seu status e da sua performance na esfera do trabalho burocraticamente valorizado, e as aspirações sociais são pauperizadas, pois são canalizados quase unicamente para a detenção de um emprego, muitas vezes desconectado de reais possibilidades de auto-realização" (Serva, 1997).

Para Guerreiro Ramos a grande maioria das organizações produtivas tem como referência a razão instrumental, determinando o padrão de sucesso a ser atingido, orientado pelas leis do mercado. Longe das premissas ético-valorativas, o ambiente organizacional tornou-se propício aos abusos do poder, à dominação, lançando os indivíduos a uma competição permanente, produtora de ansiedades e de patologias psíquicas (Guerreiro Ramos, 1981 citado por Serva, 1997). Neste processo de consolidação da racionalidade instrumental como dimensão norteadora de praticamente todas dimensões das experiências associativas humanas, a racionalidade substantiva tende a ser esquecida.

A racionalidade substantiva, a despeito de ser uma instigante e fecunda categoria de análise, dada sua base ética preponderante sobre qualquer outra; sua dimensão intrínseca e natural ao ser humano, é sistematicamente alijada à marginalidade. Sua capacidade de conduzir os indivíduos ao alcance de sua autorealização em busca da emancipação e satisfação social, é transformada em "irracionalidade" (Marcuse, 1996).

Sintonizado com a crítica de Marcuse (1996), Habermas (1975) descreve a racionalidade técnica como instrumental, tendendo a ser governada pelo teórico, com enfoque no controle por meio do desenvolvimento 
de cadeias de meios e fins. Cumpre ressaltar que o oposto para Habermas seria a racionalidade prática que focaliza o processo de compreensão e determinação mútua dos fins a serem atingidos, em lugar do controle (Alvesson e Deetz, 1998).

Em um sistema equilibrado, essas duas formas de racionalidade -instrumental e substantiva - tornam-se complementares. No entanto, na situação social contemporânea, a forma e conteúdo da ciência social moderna e a constituição social de especialização estão muito mais sintonizadas com estruturas organizacionais produtoras da dominação pela racionalidade técnica ou instrumental (Alvesson e Deetz, 1998).

À medida que a racionalidade técnica amplia sua capacidade de domínio, ela reivindica para si todo o conceito de racionalidade, condenando as possíveis formas alternativas de associação ou de existência ao campo do irracional. Para ser melhor compreendidas, as dimensões colonizadoras da racionalidade instrumental podem ser identificadas a partir de seus efeitos sobre a civilização do trabalho.

\section{RACIONALIDADE INSTRUMENTAL E SEUS EFEITOS NAS RELAÇÕES DE TRABALHO}

Uma das estratégias para explicitar a materialidade de determinado conceito é tornando evidentes seus possíveis efeitos. Neste particular, as expressões da racionalidade instrumental, entendida aqui como sustentáculo da civilização do trabalho, são a reestruturação produtiva, a revolução tecnológica e o processo de trabalho na saúde. Por meio destes três efeitos, será possível perceber como a racionalidade instrumental tende a colonizar todas as dimensões da vida associativa, negando espaços para a substantividade e para a auto-realização humana.

\section{Reestruturação produtiva}

O processo de reestruturação produtiva torna visível um conjunto de transformações nas relações capitaltrabalho ocorridas na década de 1970, marcado por um período de oscilações, incertezas, enfim, de uma série de novas experiências nos domínios da organização industrial e na vida social e política.

Esta fase, para alguns autores como Coriat (1988) e Harvey (1993), é considerada como sendo um processo de ruptura com as formas de organização tayloristas/fordistas. No entanto, para outros autores como Leite (1994), Braga (1995), Antunes (1997), Faria (1997), Lojkine (1995) e Castells (1999) este cenário se configura como continuação e, também, como sofisticação do processo de exploração do sobretrabalho.

Neste novo contexto, as empresas começam a introduzir algumas técnicas japonesas de produção, como os Círculos de Controle de Qualidade (CCQ), bem como novos equipamentos de base microeletrônica, como os robôs, as máquinas operatrizes controladas por computador, chamadas de Computer Numerical Control (CNC), os quais foram sendo acompanhados por inovações de produto e processo (Leite, 1994; Gonçalves \& Gomes, 1993; Harnecker, 2000).

A introdução destas novas tecnologias no processo produtivo revela a exigência da própria dinâmica 
capitalista, de superar suas contradições inerentes ao próprio processo de acumulação. A automação industrial no processo produtivo impõe modificações na organização do trabalho, buscando recuperar a perda da eficiência nas formas tradicionais de gestão (Faria, 1997).

Embora as estratégias seguidas pelas empresas em cada um destes momentos sejam bastante diferenciadas, é possível destacar um elemento comum a elas que é seu caráter limitado e reativo, identificando um processo de "modernização conservadora" (Leite, 1994; Tavares \& Assis, 1986), priorizando-se aspectos quantitativos em detrimento de aspectos qualitativos. Se por um lado as novas tecnologias modernizam os setores produtivos com equipamentos, computadores, sistemas gerenciais etc., por outro, a produtividade e a qualidade do trabalho e do produto do trabalho deixam a desejar.

Juntamente com estas inovações, as organizações pressupõem que o trabalhador tenha um comportamento flexível. Espera-se que com uma certa flexibilidade, seja possível gerar liberdade pessoal, imaginando que um trabalhador adaptável ao sistema é livre e capaz da mudança. No entanto, a repulsa à rotina e a busca pela flexibilidade produziram novas estruturas de poder e controle, em vez de criarem condições de liberdade. Este novo sistema de poder se apresenta por meio de três elementos: reinvenção descontínua de instituições, especialização flexível e concentração de poder sem centralização. Estes três elementos estão presentes nas constantes reestruturações das organizações como: redução do número de funcionários, alterações nos sistemas produtivos, redução da jornada, alteração na hierarquia das organizações, forças estas que dobram as pessoas à mudança.

\section{Revolução tecnológica}

No bojo da revolução tecnológica há transferência, para as máquinas, de um novo tipo de funções cerebrais abstratas, o que propriamente caracteriza a automação, tendo como conseqüência fundamental, o deslocamento do trabalho humano da manipulação para o tratamento de símbolos abstratos - e, pois, deslocando-o para o tratamento da informação.

Desta forma, para Lojkine (1995), a revolução informacional nasce da oposição entre a revolução da máquina-ferramenta, fundada na objetivação das funções manuais, e a revolução da automação, baseada na objetivação de certas funções cerebrais desenvolvidas pelo maquinismo industrial.

A introdução de tecnologias físicas no processo de produção exige modificações na tecnologia de gestão com a intenção de promover maior integração entre gestores e trabalhadores (Faria, 1997), compreendendo um conjunto de técnicas, instrumentos ou estratégias utilizadas para controlar o processo produtivo, procurando otimizar os recursos nele empregados. A aplicação desta tecnologia cresceu rapidamente no setor industrial, buscando-se o aumento da produtividade de fatores como capital, trabalho e recursos materiais, assim como procurando consolidar a competitividade das indústrias nacionais.

As implicações da nova tecnologia sobre o processo produtivo foram pesquisadas por Loyola (1995), tomando-se por base trabalhadores da Indústria de Refrigeração do Paraná. Os resultados da pesquisa apontaram para:

a) desqualificação de uma maioria em detrimento de uma minoria, prevalecendo o saber instrumental; 
b) redução do volume de empregos como conseqüência de um aumento da produtividade e da racionalização do tempo necessário à produção;

c) satisfação dos trabalhadores para as condições de trabalho decorrentes da automação em contraposição a um aspecto desfavorável, o stress provocado pela intensificação do trabalho automatizado;

d) ampliação do controle sobre o processo de trabalho devido às facilidades oferecidas pela automação microeletrônica;

e) benefícios em relação à qualidade dos produtos, apresentando uma maior conformidade entre o planejado e o produzido com reduzidos índices de desperdício industrial.

No setor de serviços a aplicação de novas tecnologias vem crescendo ao longo dos anos, uma vez que

"os computadores e seus terminais, nas suas mais diversas formas (mini, micro, calculadoras sofisticadas, caixas registradoras eletrônicas) estão, por definição, simplificando drasticamente uma série de operações rotineiras ligadas ao processamento de dados e informações padronizadas nos escritórios, no comércio, serviços bancários...” (Tauille, 1988, p. 21).

Esta última afirmação está inserida em uma série de discussões históricas sobre tendências do pósindustrialismo e do informacionalismo. Castells (1999), por exemplo, afirma que as teorias do pósindustrialismo e informacionalismo utilizam como prova empírica da mudança histórica o aparecimento de uma nova estrutura social caracterizada pela mudança de produtos para serviços, pelo surgimento de profissões administrativas e especializadas, pelo fim do emprego rural e industrial e pelo crescente conteúdo de informação no trabalho das economias mais avançadas.

O autor, no entanto, propõe uma abordagem diferente. Sua tese é a da interconexão progressiva entre todos os subsistemas produtivos, sejam eles de serviços ou industriais. Embora admita tendência comum na evolução da estrutura do emprego, típica das sociedades informacionais, também acredita em uma variação histórica de modelos de mercado de trabalho segundo instituições, cultura e ambientes políticos específicos.

Para Castells (1999), o conceito de serviços é considerado ambígüo e tem sido usado como um conceito residual que abarca tudo o que não é agricultura, mineração, construção, empresas de serviço público ou indústria. As tentativas de definir serviços por algumas características intrínsecas, como sua intangibilidade em oposição à materialidade de produtos ficaram sem sentido com a evolução da economia informacional. Software para computadores, produção de vídeos, projeto de microeletrônica, agropecuária com base em biotecnologia e muitos outros processos cruciais característicos das economias mais ricas juntam seu conteúdo de informação ao suporte material do produto, impossibilitando a distinção dos limites entre bens e serviços.

Analisando o processo de tecnificação da medicina no Brasil, Maia (1984), afirma que os serviços de atenção à saúde também cumprem determinadas funções dentro do processo produtivo de economias capitalistas. Estes serviços, entendidos como unidades produtivas, consomem produtos de outras indústrias, como a farmacêutica e de equipamentos e instrumentos médicos, atendendo em certa medida às necessidades de desenvolvimento e de lucro das referidas indústrias. 
Na avaliação de Kawamura (1987), o avanço tecnológico em áreas sociais como saúde, educação, artes etc., vem caracterizando a inserção destas áreas, antes consideradas fora do processo produtivo, na dinâmica das relações capitalistas, organizadas sob o parâmetro do lucro. Segundo a autora, a defesa da modernização sistemática da área de saúde, em especial, favorece o chamado complexo médico-industrial: empresas médicas, laboratórios, indústrias farmacêuticas e de equipamentos, hospitais e afins. No entanto, no Brasil, a incorporação de novas tecnologias tende a ser alienada dos reais problemas de saúde do país, acentuando as contradições que emanam das próprias formas de organização da assistência médica.

A autora alerta para o caráter oneroso e elitista em que se organiza a assistência médica. Pois, o modelo médico ao se basear na sofisticação tecnológica, torna-se caro inclusive para os recursos públicos. Estes são inadequadamente distribuídos, pois destinam-se poucos recursos para a medicina preventiva e enormes quantias para a medicina assistencial paliativa.

Se, por um lado, as inovações tecnológicas, ao mesmo tempo que exigem a superespecialização e a requalificação profissional, tornam as condições de trabalho precárias, rotinizadas, mal pagas, desestimulando o investimento dos profissionais em si, por outro, estimula o consumo de medicamentos de última geração, privilegiando o caráter curativo e individual da assistência médica em detrimento de uma medicina preventiva e coletiva. Esta prática torna-se excludente, pois a maioria da população fica longe dos efeitos benéficos da medicina avançada.

\section{O processo de trabalho na saúde}

O processo de trabalho em saúde tem suas particularidades. Atualmente, o atendimento à saúde, prestado à população, desenvolve-se em serviços de saúde institucionalizados, que organizam o seu funcionamento e processo de produção dentro de determinados contextos.

No âmbito institucional, verifica-se que a lógica da organização capitalista do trabalho também se introduz na organização da assistência à saúde, uma vez que esta resulta do trabalho coletivo, parcelado em diversas atividades e exercido por profissionais de saúde e outros profissionais ou trabalhadores treinados para atividades específicas.

A prestação de serviços à saúde pode assumir formas diversas, como a realização de uma consulta, uma cirurgia, um exame-diagnóstico, a indicação de uma medicação específica e outras orientações gerais. Esta assistência é realizada por profissionais que detêm conhecimentos específicos e que podem atuar e intervir em atividades de cunho investigativo, preventivo, curativo ou com o objetivo de reabilitação.

O processo de trabalho dos profissionais de saúde tem como finalidade a ação terapêutica de saúde, como objeto o indivíduo ou grupos de pessoas, como instrumento de trabalho os instrumentos e o saber de saúde e como produto final a própria assistência à saúde que é produzida no mesmo momento em que é consumida (Pires, 1998).

Nas organizações públicas de saúde, embora não se possa falar em trabalho produtivo, pode-se afirmar que se implementa, cada vez com maior ênfase, critérios de produção tipicamente capitalistas, o que significa a adoção de uma lógica "produtivista", motivo pelo qual ganham destaque as práticas gerenciais, que visam 


\section{GESTÃO DE PESSOAS - COMPLEMENTARIDADE ENTRE RACIONALIDADES NA CONSTRUÇÃO DA IDENTIDADE PROFISSIONAL \\ Sandra Mara Maciel de Lima - Kátia Regina Hopfer - José Edmilson de Souza-Lima}

aumentar a produtividade do trabalho, significando, no caso estudado, maior volume de atendimento, maior agilização de procedimentos administrativos, mais rapidez nos agendamentos e nos encaminhamentos dos pacientes, maior controle sobre o histórico dos pacientes, entre outros.

Percebe-se que nem mesmo o processo de trabalho em uma atividade substantiva por excelência, a atividade na saúde, consegue ficar isenta do poder colonizador e implacável da racionalidade instrumental. É inevitável a influência desta colonização no processo de construção da identidade do profissional em geral e do médico, em particular.

\section{A CONSTRUÇÃO DA IDENTIDADE NO CONTEXTO DO TRABALHO}

A identidade é um elemento-chave da realidade subjetiva porque está associada à relação dialética com a sociedade e por ser constituída e constituinte a partir dos processos sociais. Uma vez cristalizada é mantida, modificada ou mesmo remodelada pelas relações sociais. E, por sua vez, os processos sociais implicados na formação e conservação da identidade são determinados pela estrutura social (Berger \& Luckmann, 1985).

O trabalho surge como uma das formas de relação do homem com o meio no qual está inserido. Trabalho como forma de realização, como disciplina, como forma de sobrevivência. Por meio do trabalho o homem pode modificar seu meio e modificar a si mesmo. Sendo assim,

"a vida organizacional somente pode ser apreendida e analisada de forma interacionista: não é o ambiente que determina o ser da organização e tampouco é o ser da organização que determina o ambiente, mas a relação entre ambos é que determina o que s̃o, como são e por que são" (Faria, 2000).

Nesta perspectiva, o sujeito não constrói sua própria identidade somente a partir de si mesmo, necessita do olhar do outro, do julgamento do outro (Dejours, 1999b). E no trabalho, o que o sujeito procura fazer que seja reconhecido é o seu fazer e não o seu ser.

Sendo assim, o indivíduo ao ingressar em uma organização (empresa, família, religião) faz parte do jogo social vigente. Este jogo social é a luta pelo reconhecimento ou o desejo do reconhecimento. Cada indivíduo manifesta seus desejos, seus interesses pessoais que precisam ser reconhecidos pelos demais. Esta necessidade pode ser identificada como a luta pelo reconhecimento do desejo, como condição de existência, de sobrevivência dentro dos grupos ou organizações (Enriquez, 1994 e 1997; Faria, 1999).

Da mesma forma, em geral o indivíduo tem, também, o desejo de ser reconhecido como um dos membros do grupo. Esta aceitação mútua determinará a diferenciação, o grupo passa a ser um corpo social e não apenas um aglomerado de indivíduos.

Prazer e sofrimento são vivências subjetivas, muitas vezes, inconscientes, resultantes do confronto entre a história de vida do indivíduo e a realidade de trabalho. Para Dejours (1994, 1999a), prazer e sofrimento no trabalho estão associados à organização do trabalho, caracterizada pelo conteúdo da tarefa e relações sócioprofissionais, a qual exerce um impacto no funcionamento psíquico do trabalhador gerando sofrimento ou prazer, dependendo do quanto a tarefa é significativa para o trabalhador e se as relações com colegas e 
chefias são ou não de reconhecimento, cooperação, confiança e solidariedade.

Segundo Dejours (1999b), como o sofrimento é inerente ao mundo do trabalho, não sendo tarefa fácil eliminá-lo, é necessário que ele seja transformado. Desta forma, o sofrimento adquire sentido quando é entendido como um "trampolim" para se obter reconhecimento, satisfação e prazer no trabalho. À medida que se reconhece a qualidade do trabalho do sujeito, contribui-se para a realização do ego deste, para a construção de sua identidade e para a constituição de sua saúde mental (Dejours, 1999a). O reconhecimento é a forma específica da retribuição moral-simbólica dada ao ego, como compensação por sua contribuição à eficácia da organização do trabalho, ou seja, pelo engajamento da sua subjetividade e inteligência (Dejours, 1997).

Por este motivo o sujeito que submete seu trabalho a outros espera, em troca, o reconhecimento, pois este simboliza a retribuição fundamental da sublimação. Isto significa que a sublimação tem papel importante na conquista da identidade, pois o reconhecimento social e a identidade como condição de sublimação confere à sublimação uma função essencial à saúde mental (Dejours citado por Chanlat, 1991).

Em razão da indiferença aos desejos individuais reinante nas organizações e a competitividade excessiva, o sofrimento parece ser inevitável, pois o risco de frustração do desejo de reconhecimento é muito grande. Isso, inevitavelmente, proporciona sérios prejuízos à saúde mental dos trabalhadores (Dejours, 1999a).

O sofrimento, por sua vez, situa-se entre dois extremos que é o espaço de luta entre a saúde mental ou o bem-estar psíquico e a doença mental ou a loucura. Quando esse sofrimento não causa uma ruptura no equilíbrio psíquico é porque, certamente, o indivíduo se utiliza de defesas que lhes permitem controlar-se (Dejours, 1999b).

O estilo de vida moderno, que dá maior importância ao racional do que ao afetivo, que valoriza a competitividade constante e os padrões de qualidade e produtividade, provoca uma série de sofrimentos e deixa os trabalhadores vulneráveis a doenças como o stress, depressão, alcoolismo, desequilíbrio emocional etc. (CODO, SAMPAIO e HITOMI, 1998). Entretanto, a mecanização e a robotização que poderiam reduzir o nível de sofrimento dos trabalhadores muitas vezes contribui para agravá-lo, à medida que favorece o surgimento do sentimento de incompetência e incapacidade. Isso força o trabalhador a buscar constantemente atualização, proporcionando sobrecarga de atividades e responsabilidades. Há a sensação de não conseguir satisfazer as necessidades da organização ou do mercado.

Pagès et al (1993) argumenta que a organização tende a se tornar fonte de angústia e de prazer ao indivíduo, pois ele está ligado à organização não apenas por laços materiais e morais, por vantagens econômicas e satisfações ideológicas que ela lhe proporciona, mas também por laços psicológicos.

Segundo Dejours (1994), o trabalho pode ser fonte de equilíbrio para uns e para outros pode ser fonte de fadiga, dependendo da carga psíquica do trabalho. A carga psíquica do trabalho aparece como um regulador da carga global de trabalho e, ao permitir descarga psíquica, projeta-se como instrumento de equilíbrio para o trabalhador.

$\mathrm{O}$ trabalhador submetido às excitações provenientes do exterior ou do seu interior, dispõe de vias de descarga de sua energia, que podem ser a via psíquica, a via motora e a via visceral. A produção de 


\section{GESTÃO DE PESSOAS - COMPLEMENTARIDADE ENTRE RACIONALIDADES NA CONSTRUÇÃO DA IDENTIDADE PROFISSIONAL \\ Sandra Mara Maciel de Lima - Kátia Regina Hopfer - José Edmilson de Souza-Lima}

fantasmas agressivos pode ser a forma de representação mental para a descarga da tensão interior, já que essa forma, segundo Freud é consumidora de energia pulsional. Outra pessoa que não consegue relaxar por esse meio poderá utilizar o seu físico, como forma de descarga psicomotora, por meio de violência, atuação agressiva, fuga etc. E quando a via mental e a via motora estão fora de ação a energia pulsional pode ser descarregada pela via do sistema nervoso, que poderá atuar no processo de somatização (Dejours, 1994).

Então a carga psíquica do trabalho resulta da confrontação do desejo do trabalhador à imposição do empregador, contida na organização do trabalho, ou seja, da divisão das tarefas que atinge diretamente a questão do interesse e do tédio no trabalho e de outro lado, a divisão dos homens (hierarquia), que atinge diretamente as relações que os trabalhadores estabelecem entre si no local de trabalho. Quanto menos liberdade de organização do trabalho, maior é a carga psíquica do trabalhador; e quando não é possível a organização do trabalho pelo trabalhador, ocorre um bloqueio do aparelho psíquico na relação com a tarefa e conseqüentemente a fadiga e o sofrimento (Dejours, 1994).

Há de se notar que a produção de identidades, orientada por uma racionalidade instrumental tende a produzir indivíduos incapazes de perceber com clareza seu próprio sofrimento. Este tipo de "identidade" projeta-se como principal combustível para a própria racionalidade instrumental aumentar sua sobrevida. Daí a necessidade de se repensar a ideologia no trabalho.

\section{A ideologia no trabalho}

$\mathrm{Na}$ civilização gerida pela racionalidade instrumental, o indivíduo precisa ser conduzido à crença de que se não obedecer a certas regras estabelecidas de cima para baixo jamais conseguirá viver em harmonia com a sociedade. Essas regras são formadas por idéias de como a sociedade deve funcionar e de que forma o indivíduo deve se posicionar em relação a elas.

Esta ideologia dominante determina de que forma a sociedade deseja que o indivíduo construa a sua vida, adaptando as suas crenças e valores, fazendo os ajustes necessários na sua ética para alcançar a harmonia em um grupo social. Assim, a ideologia faz parte da vida do indivíduo, do seu espírito, do seu jeito de ser, da sua identidade (Althusser, 1999).

As ideologias fazem parte da concepção do mundo porque definem tudo que será disponibilizado como verdade. Neste enfoque, a sociedade se refere a diversas ideologias, como a ideologia religiosa, a moral e a política. Essas ideologias auxiliam o indivíduo a interpretar a realidade que se apresenta, desenvolvendo uma representação imaginária do mundo e da sua própria realidade. Essa representação é imaginária pois as condições reais de existência sobre as quais ela é desenvolvida constituem fatores de alienação para o indivíduo (Althusser, 1999). Nestes termos, um indivíduo alienado é aquele que não vive mais de acordo com a realidade, passando a viver e a acreditar em um imaginário construído a partir dessa realidade.

Para continuar a viver na sociedade moderna e trabalhar nas empresas modernas, o indivíduo desenvolve ideologias defensivas que garantem a conservação da sua moral. Estas ideologias levam o indivíduo a acreditar que as suas atitudes e ações são justificadas em nome do bem comum, da sobrevivência da empresa, da guerra com a concorrência. Assim, quando o profissional autoriza uma demissão em massa, não 
há sentimento de culpa. Os demitidos passam a ser vistos como ultrapassados, preguiçosos e inflexíveis (Dejours, 1999a).

O trabalho está cercado por uma ideologia dominante. O indivíduo que pretende exercer uma profissão e trabalhar em uma organização precisa compreender, assimilar e aceitar esta ideologia como sendo sua, agregá-la às suas crenças pessoais. Assim, as organizações são o lugar onde esta ideologia é reproduzida, unificando as diversidades e contradições existentes (Althusser, 1999).

O indivíduo, ao longo de sua vida profissional, representa diversos papéis face à sociedade, escolhendo o papel mais adequado ao ambiente externo onde ele está inserido. Ao promovendo tais adaptações, o indivíduo pode ser considerado um profissional da ideologia, à medida que desenvolve a habilidade de se adaptar e conviver com características individuais conflitantes, como por exemplo, a modéstia, a resignação, a submissão, o cinismo, a altivez, a segurança, e a grandeza (Althusser, 1999).

As organizações fornecem uma concepção de mundo conforme suas aspirações e uma interpretação da realidade coerentes com suas práticas sociais, que induzam o trabalhador a compartilhar da ideologia da empresa e a ela submenter-se. Por se caracterizar como componente essencial para o sucesso produtivo da organização, a ideologia não coage nem ameaça de forma deliberada o trabalhador para estimulá-lo a produzir mais, pois de maneira sutil ela é introjetada nas mentes do trabalhador. À medida que se efetiva a integração ideológica do trabalhador com a organização, ocorre um aumento de produtividade. Esta adesão ideológica faz com que o trabalhador se entregue de "corpo e alma" na execução do seu trabalho (Pagès et al, 1993).

A identidade que inicialmente assume a forma de um nome próprio, passa a adotar outras formas de predicações, tais como papéis. O indivíduo não mais é algo: ele é apenas o que faz (Ciampa, 1993).

Uma mulher não pode ser mãe sem ter filhos, precisa de um filho que lhe dê a identidade materna. Um homem precisa de uma esposa para ser marido. Todas as identidades exigem um outro, alguém em quem e por meio do relacionamento a auto-identidade é efetivada (Laing, 1989). "Ser é ser percebido" como dizia o filósofo irlandês Geoge Berkeley, onde permanece a idéia de que é apenas pelo outro que podemos realmente nos identificar.

Contrariamente à visão que podem ter alguns pesquisadores em ciências humanas, o ser humano não pode reduzir-se a um organismo submetido a um bombardeamento de estímulos (Skinner, 1968 citado por Chanlat, 1991). Ele também é um ser de desejo, de pulsão e de relação. É por meio das relações que ele mantém com o outro pelo jogo de identificações - introspecção, projeção, transferência etc. - que ele vê seu desejo e sua existência reconhecidos ou não (Chanlat, 1991).

É pela ação e discurso que os seres humanos revelam suas identidades pessoais e singulares (Arendt, 1989). No exercício da medicina muitas vezes os entrevistados depararam-se com situações em que nem sempre podiam desempenhar seu papel como queriam, encontrando obstáculos e reconhecendo a importância das relações políticas. Os obstáculos identificados pelos entrevistados estão associados à racionalidade instrumental que tenta negar espaços de colaboração e estimular práticas competitivas entre os profissionais. As identidades são construídas tomando como referência um outro que compete, não que coopera. Como afirma Domênico de Masi (2000), a racionalidade instrumental ao mesmo tempo que estimula as competições 
predatórias, nega veementemente práticas apoiadas em princípios da emulação solidária. Os impactos deste processo civilizatório são os mais perversos, sobretudo para os seres - a imensa maioria - que vivem do trabalho (Antunes, 1997).

\section{METODOLOGIA}

O presente artigo apresenta resultados de pesquisa desenvolvida em uma instituição médico-hospitalar de Curitiba, de médio porte, que atende a uma parcela específica da população. Um estudo exploratório que procura desvendar uma possível complementaridade entre as duas racionalidades no processo de construção da identidade do profissional da saúde, neste caso, o médico.

Para tanto, optou-se pelo estudo de caso utilizando-se entrevistas semi-estruturadas (gravadas e transcritas). O nível de análise é o organizacional e a unidade de análise é constituída pelos médicos da organização. Ao todo a organização possui 70 profissionais de saúde. Destes, 25 são médicos, 24 são enfermeiros e 21 são auxiliares. A população-alvo desta pesquisa, portanto, é composta por todos os médicos que trabalham na organização.

Devido às características próprias da população de interesse desta pesquisa, optourse pela amostragem tipo bola-de-neve. Este método é usado com o objetivo de estimar características raras na população. Trata-se de uma técnica de amostragem não-probabilística em que um grupo inicial de entrevistados é selecionado aleatoriamente. Selecionam-se os demais entrevistados com base em informações dadas pelos entrevistados iniciais. Chama-se "bola-de-neve" porque o processo pode ser executado em ondas sucessivas, obtendo-se referências ou informações a partir de referências ou informações (Malhotra, 2001).

A pesquisa realizada em 2002, portanto, contou com o resultado da aplicação de 7 (sete) entrevistas semiestruturadas aos profissionais médicos. Entre os profissionais entrevistados encontramos chefes das diversas áreas do hospital: área de medicina preventiva, área de medicina geral etc., assim como, médicos especialistas.

As entrevistas foram preparadas e analisadas pelo método de análise de conteúdo (Bardin, 1979), com o objetivo de identificar e classificar os indicadores obtidos nas mensagens gravadas. Para tanto, aplicou-se a técnica de Análise Temática das entrevistas, contagem de um ou vários temas ou itens de significação, numa unidade de codificação previamente determinada. Esta técnica permite determinar, por meio do discurso presente nas entrevistas, uma frase ou uma palavra como unidade de codificação. Por enumeração temática, foi possível levantar atitudes representativas da racionalidade instrumental e da racionalidade substantiva presente no trabalho dos profissionais, tendo como base a discussão teórica sobre o tema.

Após tratamento, estes indicadores foram agrupados em dois quadros: o Quadro 1 da racionalidade instrumental e Quadro 2 da racionalidade substantiva. A cada indicador foi associado um ou mais depoimentos de forma a demonstrar a percepção dos profissionais médicos. Os quadros foram analisados com base na discussão teórica, dando subsídios para as considerações finais. 


\section{QUADRO DE ANÁLISE.}

Sandra Mara Maciel de Lima - Kátia Regina Hopfer - José Edmilson de Souza-Lima

Os resultados das entrevistas realizadas com profissionais médicos de um Hospital de médio porte do município de Curitiba são apresentados neste tópico e representados nos Quadros 1 e 2.

Analisando as entrevistas pela técnica de "análise temática" foi possível identificar atitudes representativas da racionalidade instrumental e da racionalidade substantiva.

Os indicadores da racionalidade instrumental extraídos dos depoimentos são: rotina, hierarquia rígida, resignação à ordem estabelecida e fragmentação do conhecimento (ver Quadro 1). Indicadores que corroboram a tese da dimensão colonizadora da racionalidade instrumental, à medida que certas rotinas são impostas pela organização, bloqueando uma liberdade necessária à instauração do processo criativo no ambiente de trabalho. Um exemplo disso está expresso no depoimento que segue: “... às vezes eu acho que estou fazendo muito pouco, e que aquela rotina está me acomodando e que não está me trazendo nada, e vem aquela insatisfação. Parte de minha vida é ligada a uma instituição muito, muito rígida... a gente não tem espaço para a criatividade...”.

Quadro 1. Indicadores da racionalidade instrumental.

\begin{tabular}{|l|l|}
\hline Rotina & $\begin{array}{l}\text { “... às vezes eu acho que estou fazendo muito pouco, e que aquela rotina está } \\
\text { me acomodando e que não está me trazendo nada, e vem aquela insatisfação. } \\
\text { Parte de minha vida é ligada a uma instituição muito, muito rígida ... a gente não } \\
\text { tem espaço para a criatividade...” } \\
\text { "Você não tem como desenvolver um trabalho aqui dentro. Talvez hoje em dia } \\
\text { eu me frustre muito por não ter praticado uma medicina melhor... "Eu gostaria } \\
\text { de ter trabalhado na área de medicina e não trabalhei..." }\end{array}$ \\
\hline Hierarquia rígida & $\begin{array}{l}\text { “... na esfera organizacional, onde eu não sou muito bem querido, a minha } \\
\text { função é cobrar os vinte médicos. E eu cobro, porque aqui há uma hierarquia...” } \\
\text { "Aqui eu sou cirurgião mas não posso operar, sou chefe mas não posso } \\
\text { mandar.” }\end{array}$ \\
\hline $\begin{array}{l}\text { Resignação à ordem } \\
\text { estabelecida }\end{array}$ & $\begin{array}{l}\text { "Então é um jogo de cintura muito grande, que você tem que ter para poder } \\
\text { enfrentar tudo isso, você pode tentar melhorar a estrutura, agora mudar não tem } \\
\text { como..." } \\
\text { "... se ele trabalha dentro de uma instituição ele é obrigado a atender a certos } \\
\text { protocolos que já são criados pela própria instituição." } \\
\text { "... existe uma base que é a organização, que eu não posso mudar isso, o resto } \\
\text { flutua em volta dela, eu não posso faltar aqui, por exemplo, tenho que pedir, é } \\
\text { um esquema rígido, aqui é muito vigiado, existe toda uma regra que não existe lá } \\
\text { fora ..." }\end{array}$ \\
\hline $\begin{array}{l}\text { Fragmentação do } \\
\text { conhecimento }\end{array}$ & $\begin{array}{l}\text { "Ser médico é tratar de um setor da vida do ser humano, onde ele sofre. É } \\
\text { tratar de um sofrimento, com a angústia da parte do corpo dele." }\end{array}$ \\
\hline
\end{tabular}

Verifica-se, igualmente, a existência de uma hierarquia permeada pela rigidez na qual os médicos se sentem impossibilitados de exercer plenamente a medicina: "aqui eu sou cirurgião, mas não posso operar, sou chefe mas não posso mandar". Simultaneamente, percebe-se uma resignação à ordem estabelecida pois as políticas 
internas não podem ser modificadas: "... existe uma base que é a organização, que eu não posso mudar isso, o resto flutua em volta dela, eu não posso faltar aqui, por exemplo, tenho que pedir, é um esquema rígido, aqui é muito vigiado, existe toda uma regra que não existe lá fora...".

Constata-se, finalmente, a fragmentação do conhecimento visto que o exercício da medicina aparece dividido por áreas de especialidade médica, reproduzindo experiências devedoras da reestruturação produtiva como efeito da racionalidade instrumental: "ser médico é tratar de um setor da vida do ser humano, onde ele sofre. É tratar de um sofrimento, com a angústia da parte do corpo dele". Nestes termos, esta última acentua as angústias e o sofrimento dos médicos, negando espaços para a auto-realização humana, além de conduzir alguns profissionais à internalização da ideologia dominante da instituição na qual trabalham.

\begin{tabular}{|c|c|}
\hline \multicolumn{2}{|c|}{ Quadro 2. Indicadores da Racionalidade Substantiva } \\
\hline $\begin{array}{l}\text { Identidade/ Auto- } \\
\text { realização/ Satisfação }\end{array}$ & $\begin{array}{l}\text { “... O que eu mais gosto na profissão é quando eu atendo um paciente eu vejo que } \\
\text { eu consegui, resolvi aquela dificuldade que o paciente sofria!...Eu me sinto muito } \\
\text { feliz por isso! Isso que me gratifica ...” } \\
\text { “... ser médico é servir as pessoas..." } \\
\text { “... têm certos pacientes que exigem condições especiais. Nesse momento você } \\
\text { entra em stress porque você tem que resolver e enfrentar o problema e a instituição } \\
\text { não vai te dar esse respaldo técnico. Então você acaba entrando em atrito com a } \\
\text { chefia..." } \\
\text { “... mas eu gosto de desafio. Eu gosto de operar coisas novas, aprender coisas } \\
\text { novas. } \\
\text { "Eu gosto do novo, da descoberta". } \\
\text { "... eu me acho um cara paciente pelo menos até certo ponto tolerante, a gente tem } \\
\text { que ter um pouco de tolerância para aceitar as diferenças...” }\end{array}$ \\
\hline $\begin{array}{l}\text { Busca pelo } \\
\text { reconhecimento }\end{array}$ & $\begin{array}{l}\text { "... houve momentos em que as pessoas me reconheciam mesmo quando eu estava } \\
\text { sem uniforme, isso me traz muita satisfação, porque isso faz pra mim um sentido, } \\
\text { tudo aquilo em que eu acreditava ser adequado na minha profissão, justamente } \\
\text { fazer a diferença, no bom sentido" } \\
\text { "... quando eu consigo fazer com que as pessoas se lembrem do meu nome já é } \\
\text { uma grande coisa...”. }\end{array}$ \\
\hline Responsabilidade & $\begin{array}{l}\text { "Eu acho uma responsabilidade imensa todas as profissões, mas na nossa a gente } \\
\text { encara de frente a pessoa, a quem a gente tratou bem ou mal, errou ou acertou, } \\
\text { seus entes, e vai conviver com isto o resto da vida, identificando aquela pessoa, e } \\
\text { vendo naquela pessoa os nossos erros." } \\
\text { "Você não pode tratar o paciente como uma mera mercadoria" }\end{array}$ \\
\hline $\begin{array}{l}\text { Conhecimento } \\
\text { multidimensional }\end{array}$ & $\begin{array}{l}\text { "Em compensação tem que ser mais criado, mais treinado, não só na parte } \\
\text { profissional, como na parte ética e de filosofia". } \\
\text { "O médico é um ser... Ele é criado para dissipar as coisas sozinho. Esse é um } \\
\text { problema das faculdades, não é criado para dividir opiniões. Nem dar a sua opinião } \\
\text { e nem pedir a opinião de alguém...os médicos não são muito de trocar idéias, de } \\
\text { ceder, entendeu...Você tem que ouvir os outros. Você tem que trocar idéias." }\end{array}$ \\
\hline
\end{tabular}


Da mesma forma, os indicadores da racionalidade substantiva extraídos dos depoimentos são: identidade/auto-realização/satisfação, busca pelo conhecimento, responsabilidade e conhecimento multidimensional (ver Quadro 2). Indicadores que corroboram a tese da possibilidade sempre presente de resistência dos seres humanos. Os médicos evidenciam a necessidade da satisfação no exercício da profissão; do reconhecimento pelo trabalho realizado por parte do paciente, familiares e seus pares; da responsabilidade na tomada de decisões baseadas, muitas vezes, em observações subjetivas; e do conhecimento multidimensional que é próprio das discussões intelectuais dentro do ambiente laboral. O depoimento dos profissionais esclarece as afirmações apresentadas acima: “... o que eu mais gosto na profissão é quando eu atendo um paciente e vejo que eu consegui, resolvi aquela dificuldade que o paciente sofria!...Eu me sinto muito feliz por isso! Isso que me gratifica ..."; "... você não pode tratar o paciente como uma mera mercadoria”; “... o médico tem que ser mais criado, mais treinado, não só na parte profissional, como m parte ética e de filosofia".

Estes depoimentos são indicadores de uma racionalidade que não se resigna à instrumentalidade, uma vez que está associada à busca da auto-realização e de valores que transcendem à lógica organizacional.

Se os indicadores apresentados no Quadro 1 expressam a materialização da racionalidade instrumental, com todos os seus efeitos perversos sobre a existência humana, os indicadores apresentados no Quadro 2, além de explicitar as insuficiências da referida instrumentalidade, projeta-se como alternativa concreta de racionalidade capaz de garantir o êxito da organização sem seqüestrar a subjetividade do médico e do paciente. Neste encontro consciente das racionalidades é possível perceber não apenas a dimensão antagônica, mas sobretudo a dimensão complementar entre ambas.

\section{CONCLUSÃO}

As organizações se beneficiam do desenvolvimento da racionalidade instrumental no ambiente de trabalho. Sob a ótica do sujeito, precisa ser continuadamente estudada, pois a compreensão dos seus efeitos sobre a mente e a existência humanas, permitirá o desenvolvimento de possibilidades de resistência, muito úteis para deter as suas dimensões colonizadoras, visto que se ampliariam as chances de criar saberes alternativos a essa racionalidade.

Esta pesquisa tornou visível tanto a necessidade quanto a importância de estudos guiados por matrizes teóricas orientadas pela racionalidade substantiva nas organizações. O presente estudo representa considerável esforço nesta direção a partir do momento em que se depara com temáticas vinculadas à identidade e a auto-realização, que tendem a ampliar espaços de resistência porque ajudam a elevar a autoestima dos seres que vivem do trabalho. Se, de um lado, as angústias dos entrevistados revelaram a insatisfação provocada pela racionalidade instrumental; de outro, reivindicaram uma nova racionalidade capaz de possibilitar a auto-realização no trabalho.

Finalmente, a capacidade colonizadora da racionalidade instrumental tende a reduzir ou negar espaços para a racionalidade substantiva no processo de construção de identidades profissionais auto-realizadas. Isto nos 
conduz à percepção de que a construção da identidade profissional do médico está associada às influências e tensões perenes das duas racionalidades, uma vez que é preciso aprender a pensar não mais em termos dicotômicos e excludentes, mas em termos de complementaridade. Ao se romper com as determinações dicotômicas, estão abertas as possibilidades para as descobertas da racionalidade substantiva. Se for aceito o argumento inicial de que instrumentalidade e substantividade podem ser interpretadas como dimensões de um mesmo projeto, o da auto-realização humana, fica demonstrada a complementaridade entre as duas racionalidades que orientam as decisões dos profissionais médicos. Entretanto, é fundamental perceber que a presente pesquisa demonstra que da complementaridade entre as duas racionalidades emerge uma identidade profissional médica, ainda, predominantemente instrumental, porém, com lampejos de substantividade.

\section{REFERÊNCIAS BIBLIOGRÁFICAS}

ALTHUSSER, L. Sobre a reprodução. Petrópolis : Vozes, 1999.

ALVESSON, M.; DEETZ, S. Teoria crítica e abordagens pós-modernas para estudos organizacionais. In: CLEGG, S.R. e outros (Orgs.) Handbook de Estudos Organizacionais. São Paulo : Atlas, 1998, p. 227266.

ANTUNES, R. Adeus ao trabalho. São Paulo/Campinas : Cortez/Papirus, 1997.

ARENDT, H. A condição humana. Rio de Janeiro : Forense Universitária, 1989.

ARISTÓTELES. Os Pensadores. São Paulo: Nova Cultural, 1999.

BARDIN, L. Análise de Conteúdo. Lisboa : Edições 70, 1979.

BERGER, P.; LUCKMANN, T. A construção social da realidade: tratado de sociologia do conhecimento. Petrópolis: Vozes, 1985.

BRAGA, R. Luta de classes, reestruturação produtiva e hegemonia. In: KATZ, C; BRAGA, R.; COGGIOLA, O. Novas tecnologias: crítica da atual reestruturação produtiva. São Paulo: Xamã, 1995.

CALDAS, M. P.; WOOD Jr., T. Identidade organizacional. Revista de Administração de Empresas, v.37, n. 1, p. 6-17, jan/mar, 1997.

CASTELLS, M. A sociedade em rede. A era da informação: economia, sociedade e cultura. São Paulo: Paz e Terra, 1999. Vol.I

CHANLAT, J. Por uma antropologia da condição humana nas organizações. O indivíduo nas organizações: dimensões esquecidas. Jean-François Chanlat (Coord.) São Paulo: Atlas, 1991. V. 1.

CIAMPA, A. da C. A Estória do Severino e a História da Severina. São Paulo: Brasiliense, 1993 
CODO, W.; SAMPAIO, J.J. C.; HITOMI, A.H. Indivíduo, trabalho e sofrimento: uma abordagem interdisciplinar. 3.ed. Petrópolis: Vozes, 1998.

CORIAT, B. Automação programável: novas formas e conceitos de organização da produção. In.: SCHIMTZ, H; CARVALHO, R. Q. Automação, competitividade e trabalho: a experiência internacional. São Paulo: Hucitec, 1988.

COTTA, R. M. M. et al. O município e a nova lógica institucional do setor saúde: uma análise empírica do cenário local. Saúde em Debate. Rio de Janeiro, v. 23, n. 53, p. 54-62, set/dez, 1999.

De MASI, D. O Ócio Criativo. Rio de Janeiro: Sextante, 2000. 328p.

DEJOURS, C. Psicodinâmica do Trabalho - Contribuição da Escola Dejouriana à análise da relação prazer, sofrimento e trabalho. São Paulo : Atlas, 1994.

. O fator humano. Rio de Janeiro : FGV, 1997.

. A banalização da injustiça social. Rio de Janeiro : FGV, 1999a.

- Conferências Brasileiras: identidade, reconhecimento e transgressão no trabalho. São Paulo: Fundap: EAESP/FGV, 1999b.

ENRIQUEZ, E. Psicossociologia: análise social e intervenção. Petrópolis: Vozes, 1994.

. A organização em análise. Petrópolis: Vozes, 1997.

FARIA, J. H. de. Tecnologia e processo de trabalho. Curitiba: Editora da UFPR, 1997.

Relações de poder nas organizações e nas instituições da sociedade. Curitiba: UFPR/CEPPAD,

1999.

. Economia do Poder. Texto. Curitiba : UFPR/CEPPAD, 2000.

GONÇALVES, J. E. L.; GOMES, C. de A. A tecnologia e a realização do trabalho. Revista de Administração de Empresas, v. 33, n.1, p. 106-121, jan/fev, 1993.

GUERREIRO RAMOS, A. A Nova Ciência das Organizações: uma reconstrução da riqueza das nações. 2.ed. Rio de Janeiro : Editora da FGV, 1989.

HABERMAS, J. Técnica e Ciência como Ideologia. In: Os Pensadores, São Paulo, Abril Cultural, 1975.

HARNECKER, M. Tornar possível o impossível: a esquerda no limiar do século XXI. São Paulo: Paz e Terra, 2000.

HARVEY, D. Condição pós-moderna. São Paulo: Loyola, 1993.

KAWAMURA, L. K. Tecnologia e saúde nas diferentes perspectivas de entidades associativas de médicos. 
LAING, R.D. O eu e os outros: o relacionamento interpessoal. Petrópolis, 1989.

LEITE, M. de P. Reestruturação produtiva, novas tecnologias e novas formas de gestão da mão-de-obra. In: O mundo do trabalho : crise e mudança no final do século. OLIVEIRA, C. A. B. de, et al (Orgs.), São Paulo: Scritta/Cesit/Unicamp, 1994.

LOJKINE, J. A revolução informacional. São Paulo: Cortez, 1995.

LOYOLA, S. Os reflexos da automação sobre o processo produtivo: o caso da Indústria de Refrigeração Paraná. Curitiba, 1995. Dissertação de Mestrado em Administração: Estratégias e Organizações - Setor de Ciências Sociais Aplicadas, Universidade Federal do Paraná.

MACHADO, M. H. Trabalhadores da saúde: um bem público. Saúde em Debate. Simpósio. n. 48, p. 5457, set, 1995.

MAIA, P. R. da S. Reflexões sobre o processo de tecnificação da medicina no Brasil. Revista de Administração Pública, v 18, n. 4, p. 100-24, out/dez, 1984.

MALHOTRA, N. K. Pesquisa de Marketing: uma orientação aplicada. 3ed. Porto Alegre : Bookman, 2001 .

MARCUSE, H. Algumas implicações sociais da tecnologia moderna. Revista de Estudos Marxistas, n.1, set/dez., 1996.

PAGÈS, M. et al. O poder das organizações. A dominação das multinacionais sobre os indivíduos. 3.ed. São Paulo: Atlas, 1993.

PIRES, D. Reestruturação produtiva e trabalho em saúde no Brasil. São Paulo: Confederação Nacional dos Trabalhadores em Seguridade Social - CUT, Annablume, 1998.

SERVA, M. Abordagem substantiva e ação comunicativa: uma complementaridade proveitosa para a teoria das organizações. Revista de Administração Pública, v. 31, n.2, p. 108-134, mar/abr, 1997.

SOUZA-LIMA, J. E. de. O conceito de racionalidade no debate ambiental contemporâneo. Doutorado em Meio ambiente e Desenvolvimento (texto), 2002.

TAUILE, J. R. Automação microeletrônica e competitividade : tendências no cenário internacional. In.: SCHIMTZ, H; CARVALHO, R. Q. Automação, competitividade e trabalho: a experiência internacional. São Paulo: Hucitec, 1988.

TAVARES, M. da C.; ASSIS, J. C. de. O grande salto para o caos. 2.ed. Rio de Janeiro: Zahar, 1986.

\section{Artigo recebido em 09.07.2003. Aprovado em 21.01.2004.}




\section{Sandra Mara Maciel de Lima}

Professora da Unibrasil - Complexo de Ensino Superior do Brasil. Mestre em Administração pela UFPR. Economista da Universidade Federal do Paraná.

Interesses de pesquisa : Relações de trabalho; Subjetividade; Relação entre sociedade e natureza; Impactos da tecnologia sobre o trabalho no setor de serviços.

E-mail: $\underline{\text { sandramaciel@avalon.sul.com.br }}$

Endereço:Rua Sargento Lafayette, 2211 - Bloco 7 - Ap. 102 - Curitiba - PR. 82515-090.

\section{Kátia Regina Hopfer}

Coordenadora e Professora do Curso de Ciências Contábeis da Unibrasil - Complexo de Ensino Superior do Brasil. Mestre em Administração pela UFPR.

Interesses de pesquisa : Gestão empresarial; Controle social

E-mail: hopfer@terra.com.br

Endereço: Rua Almirante Tamandaré nº 1408 - Apto. 52 - Curitiba - PR, 80040-110.

\section{José Edmilson de Souza-Lima}

Professor das Disciplinas de Humanas da FAE Business School. Doutorando em Meio Ambiente e Desenvolvimento pela UFPR. Mestre em Sociología Política pela UFSC.

Interesses de pesquisa : Ética, Responsabilidade Social, Relação entre sociedade e natureza.

E-mail: edmilson@bbs2.sul.com.br

Endereço:Rua Sargento Lafayette, 2211 - Bloco 7 - Ap. 102 - Curitiba - PR, 82515-090. 